\title{
Viabilidade de diferentes sistemas de tratamento de esgoto na bacia hidrográfica das nascentes do córrego Chibarro, São Carlos - SP
}

Feasibility of different wastewater treatment systems in the watershed of the Chibarro stream springs, São Carlos - SP

Viabilidad de diferentes sistemas de tratamiento de aguas residuales en la cuenca hidrográfica de las nacientes del arroyo Chibarro, São Carlos - SP

Bene Eloi Mendes Camargo Graduando em Gestão e Análise Ambiental, UFSCar, Brasil bn.camargo@gmail.com

Karielle Ferreira da Silva Graduando em Gestão e Análise Ambiental, UFSCar, Brasil karielleferreira@gmail.com

Rochele Amorim Ribeiro Professora Doutora, DECIV - UFSCar, Brasil. rochele@ufscar.br 

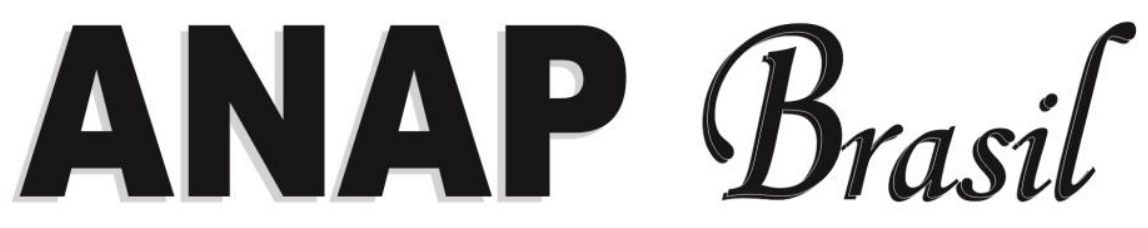

ISSN 1984-3240

V. 12 , n. 26

\section{RESUMO}

O esgoto doméstico se apresenta como um fator de alto investimento para o município. Políticas têm sido montadas e executadas para angariamento de subsídios e auxílios para lidar com esse problema. No município de São Carlos - SP a estação principal de tratamento de esgoto foi conseguida com a premiação que custeou cerca de um terço de seu valor de implantação. E o custo de operação da estação de tratamento de esgoto permanece um alto ônus à sociedade e ao bolso do consumidor. Os métodos aplicados utilizaram imagens de satélite e dados do IBGE para determinar parâmetros de crescimento, dados históricos para uma perspectiva do volume de esgoto que a população da expansão urbana gerará e uma análise das tecnologias de tratamento e de seus custos de implementação e manutenção/operação para um comparativo com os parâmetros de custos atuais do sistema de tratamento de efluentes do município. Como resposta observou-se que sistemas de tratamento descentralizados apresentam menor custo de implementação quando comparado com a ampliação de um sistema já existente. Ademais, que os custos de manutenção/operação de tratamentos mais compactos são menores que os de grandes tratamentos, mesmo quando comparada a fração correspondente de usuários dos sistemas.

PALAVRAS-CHAVE: Descentralização, Tratamento de esgoto, Bacia Hidrográfica

\section{ABSTRACT}

Domestic wastewater presents itself as a factor of high investment for the municipality. Policies have been set up and implemented to raise subsidies and aid to deal with this problem. In the municipality of São Carlos - SP, the main wastewater treatment station was obtained with the award that cost about a third of its value of implantation. And the cost of operating the sewage treatment plant remains a heavy burden on society and the consumer's pocket. The applied methods used satellite images and IBGE data to determine growth parameters, historical data for a perspective of the volume of sewage that the urban expansion population will generate and an analysis of treatment technologies and their implementation and maintenance / operation costs for a comparison with the current cost parameters of the municipal effluent treatment system. As a response, it was observed that decentralized treatment systems have lower implementation costs when compared to the expansion of an existing system. In addition, the maintenance / operation costs of more compact treatments are smaller than those of large treatments, even when compared to the corresponding fraction of users of the systems.

KEYWORDS: Decentralization, Wastewater Treatment, Watershed

\section{RESUMEN}

El alcantarillado doméstico se presenta como un factor de alta inversión para el municipio. Las políticas han sido montadas y ejecutadas para recaudar subvenciones y ayudas para hacer frente a este problema. En el municipio de São Carlos - SP la estación principal de tratamiento de aguas residuales fue lograda con la premiación que costeó cerca de un tercio de su valor de implantación. Y el costo de operación de la estación de tratamiento de aguas residuales sigue siendo un alto cargo a la sociedad y al bolsillo del consumidor. Los métodos aplicados utilizaron imágenes de satélite y datos del IBGE para determinar parámetros de crecimiento, datos históricos para una perspectiva del volumen de desagüe que la población de la expansión urbana generará y un análisis de las tecnologías de tratamiento y de sus costos de implementación y mantenimiento / operación para un comparativo con los parámetros de costos actuales del sistema de tratamiento de efluentes del municipio. Como respuesta se observó que sistemas de tratamiento descentralizados presentan menor costo de implementación en comparación con la ampliación de un sistema ya existente. Además, que los costos de mantenimiento / operación de tratamientos más compactos son menores que los de grandes tratamientos, incluso cuando se compara la fracción correspondiente de usuarios de los sistemas.

PALABRAS CLAVE: Descentralización, Tratamiento de aguas residuales, Cuenca Hidrográfica 


\section{INTRODUÇÃO}

Segundo Teodoro (2007), as definições propostas para bacia hidrográfica assemelham-se ao conceito dado por Barrella et al (2001), na qual é definido como um conjunto de terras drenadas por um rio e seus afluentes, formada nas regiões mais altas do relevo por divisores de água, onde as águas das chuvas, ou escoam superficialmente formando os riachos e rios, ou infiltram no solo para formação de nascentes e do lençol freático.

A bacia enquanto unidade coletora das águas do ciclo natural, tem papel preponderante quanto de sua ocupação para a qualidade da água que disponibilizará. E o comprometimento da qualidade da água para fins de abastecimento público é decorrente de poluição causada por diferentes fontes, tais como efluentes domésticos, efluentes industriais e deflúvio superficial urbano e agrícola. Os efluentes domésticos, por exemplo, são constituídos basicamente por contaminantes orgânicos, nutrientes e microorganismos, que podem ser patogênicos (MERTEN et. al, 2002).

A maioria dos problemas sanitários que afetam a população relaciona-se com a devolutiva dos efluentes às bacias hidrográficas. Os problemas de saneamento tornam-se cada vez mais difíceis de serem resolvidos e com um maior custo de implantação e manutenção da infraestrutura de serviços. $O$ impacto da falta do saneamento básico sobre a saúde no meio urbano vem se tornando cada vez mais frequente, principalmente nas comunidades mais carentes. Nesse sentido, o saneamento básico é fundamental na prevenção de doenças, e uma das formas de fazê-lo é através do cuidado com a higiene, da limpeza do ambiente e da alimentação (RIBEIRO, J. W.; ROOKE, J. M. S., 2010).

Com os avanços dos estudos dos Impactos Ambientais foram disponibilizadas ferramentas de mitigação de impactos negativos ou potencialização dos positivos na implantação do Sistema de Gestão Ambiental (SGA) em Estações de Tratamento de Esgotos Domésticos (ETE). A importância do seu desempenho ambiental tem repercussões locais, que envolvem solo, ar e recursos hídricos (VAZ, 2003).

Alguns compostos orgânicos presentes nos esgotos sanitários exercem efeitos tóxicos sobre animais silvestres, tais como a desregulação endócrina, tendo o potencial de afetar adversamente a saúde humana. Esses contaminantes apresentam grande diversidade de natureza química e provém das mais variadas fontes os quais são introduzidos no meio ambiente via esgoto doméstico, seja ele tratado ou não (LEITE, 2010).

Sob o ponto de vista técnico, social e ambiental, e considerando que um projeto é viável, é imprescindível a realização de estudos de viabilidade econômica. Os recursos naturais e financeiros à disposição de novos projetos estão cada vez mais escassos, o que torna imperativa a necessidade de análise das melhores alternativas de projeto, que minimizem os custos de implantação e operação, sem comprometimento dos aspectos técnicos, sociais e ambientais (GOMES, 2009).

$\mathrm{Na}$ área de saneamento básico, a necessidade de estudos criteriosos de viabilidade econômica ocorre em praticamente todos os projetos, por envolverem somas elevadas de investimentos 


\section{ANAP

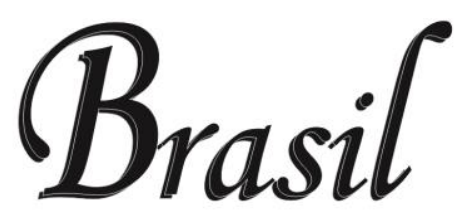 \\ ISSN 1984-3240 v. 12, n. 26}

\section{REVISTA CIENTÍFICA}

região idealizada como área de expansão pelo plano diretor do município de São Carlos, que também é conhecido como a "Capital da Tecnologia", cuja economia é fundamentada na indústria e na agropecuária. Segundo o IBGE (2018), a população de ambos os municípios juntos é de 280 mil habitantes (35 mil Ibaté e 245 mil São Carlos).

Figura 1: Localização da área de estudo.

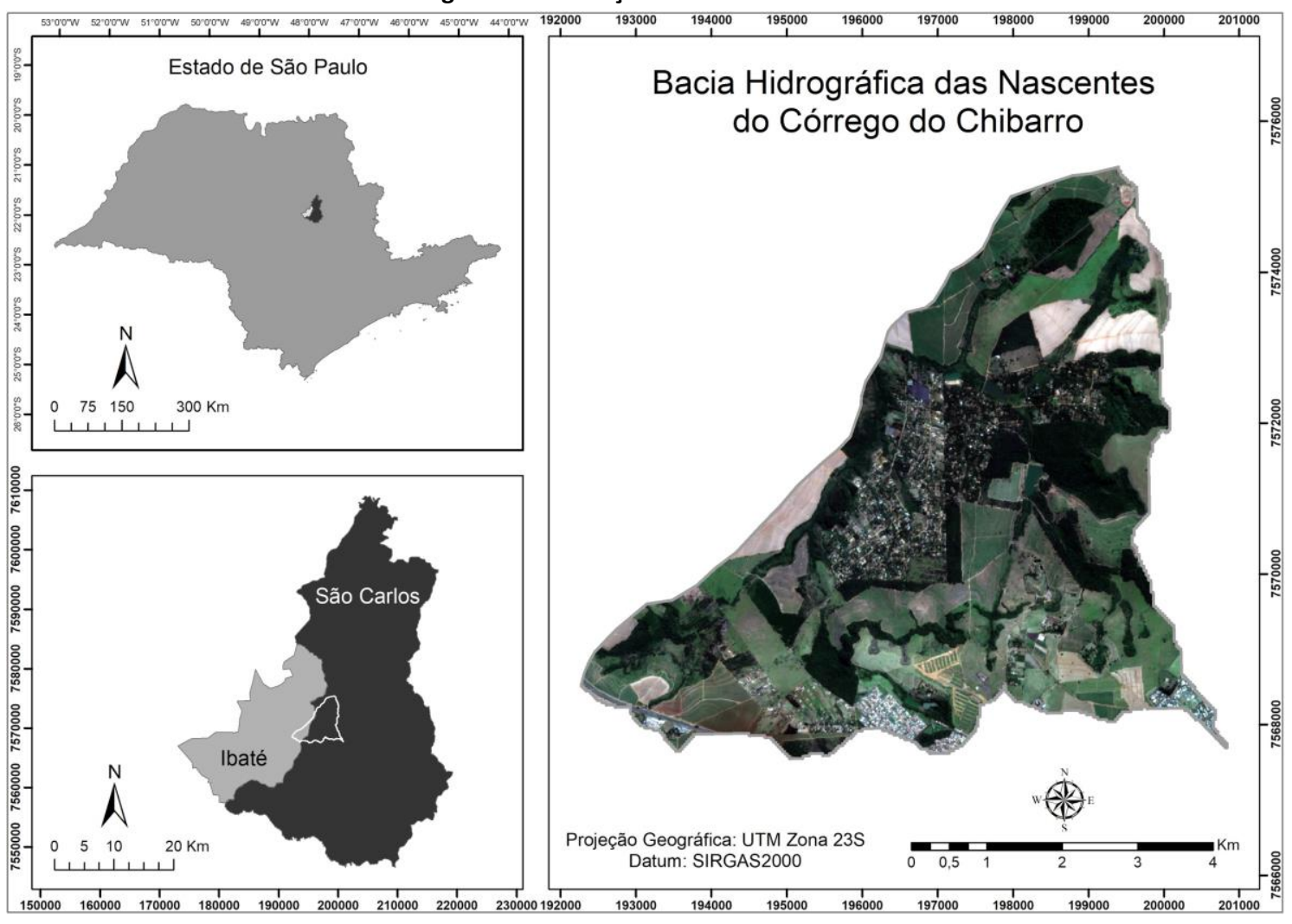

Fonte: Os autores.

Esta bacia é integrante da UGRHI 13 (Unidade de Gerenciamento de Recursos Hídricos 13 Tietê/Jacaré). As nascentes alimentam o rio Chibarro, afluente do lado direito do Rio JacaréGuaçu, que por sua vez é um afluente norte do Rio Tietê. Segundo Stanganini et al. (2016), a bacia está dividida em seus usos da terra, com aproximadamente $55 \%$ de atividades antrópicas agrícolas, $10 \%$ de área urbanizada e mais de $32 \%$ de vegetação remanescente.

A bacia compreende uma área total de 3.439 ha (IBGE, 2018). E apresenta um tempo de concentração mediano e não fortemente propenso a picos de enchente (índice de compacidade 1,644 - não sujeita a enchentes - e fator de forma 0,718 - medianamente sujeita a enchentes).

A bacia apresenta uma densidade de drenagem regular $\left(1,125 \mathrm{~km} / \mathrm{km}^{2}\right)$. Sendo que $56,85 \%$ dos corpos hídricos são de 1ạ (primeira) ordem, 29,09\% de segunda (2aㅡ) ordem, e 14,06\% das extensões dos corpos hídricos são categorizados na terceira ( $3^{3}$ ) ordem. 

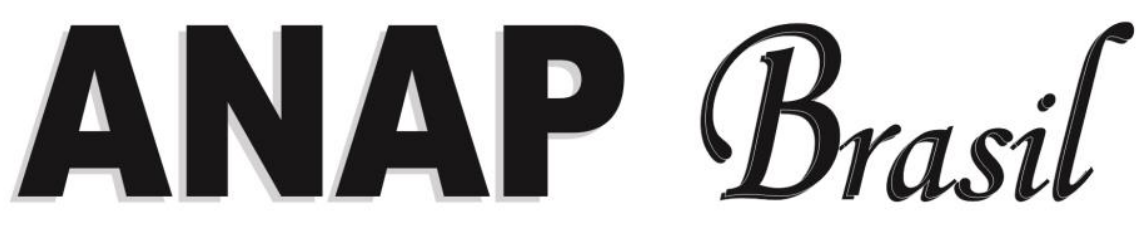

ISSN 1984-3240

v. 12, n. 26

\section{REVISTA CIENTÍFICA}

Figura 2: Diagrama dos procedimentos metodológicos.

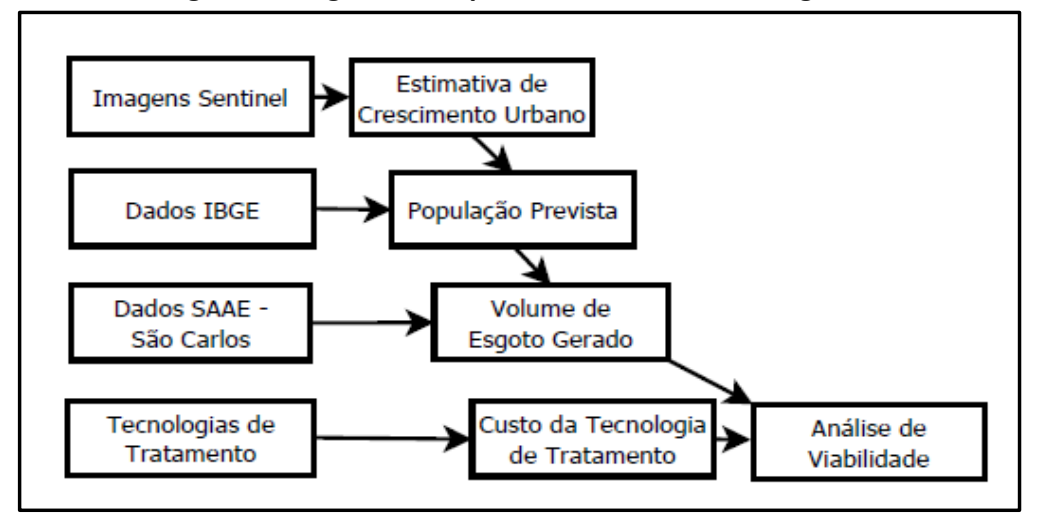

Fonte: Os autores.

A etapa inicial do projeto consistiu-se em um levantamento de informações e a formação de um banco de dados. As pesquisas foram realizadas através de levantamentos em fontes bibliográficas, bancos de dados digitais, fontes de dados disponíveis na Internet e legislações pertinentes.

Além da busca pelos parâmetros de produção de esgoto por dia e uma estimativa de custo das diferentes técnicas de tratamento de esgoto. Para realização da análise comparativa desses custos da implantação dos sistemas de tratamento, realizou-se uma análise das planilhas de orçamento produzidas pelos autores.

Os dados para as características físicas da Bacia Hidrográfica foram buscados através do sítio do Instituto Brasileiro de Geografia e Estatística (IBGE, 2018), do sítio do United States Geological Survey (USGS, 2018) e nos materiais complementares dos orientadores do projeto, de onde imagens e informações foram trabalhadas com o auxílio do Software ArcGIS 10.5.

Das imagens produzidas realizou-se um levantamento assistido da caracterização dos usos da terra, seguido por um refinamento dos limites destas áreas. Foram evidenciadas as Áreas Antrópica não Agrícola (IBGE, 2013), da qual a classificação Áreas Urbanizadas foi tipificada, pelos autores, em: ocupação consolidada urbana adensada, ocupação consolidada urbana rareada (condomínios de chácaras), ocupação urbana em expansão adensada e ocupação urbana rareada. Classificação na qual auxiliou as estimativas de densidade populacional.

Esta estimativa de densidade populacional foi utilizada para prospectar a demanda de tratamento originada pela produção de esgoto doméstico. Onde a vazão auxiliou no cálculo dos custos, priorizando a escolha pela tecnologia de tratamento de esgoto.

Os parâmetros para a identificação do tipo de tratamento foram: o volume de efluente a se tratar, a área exigida pelo tratamento e o custo de implantação e manutenção/operação dos sistemas de tratamento, respectivamente nessa ordem. Sendo que as etapas para o tratamento do esgoto podem ser descritas como:

1. Tratamento primário: De ordem física, composto principalmente por unidades de operações unitárias, que são responsáveis pela remoção de sólidos sedimentáveis e flutuantes, como parte da matéria orgânica presente no esgoto (PRADO, 2006). 

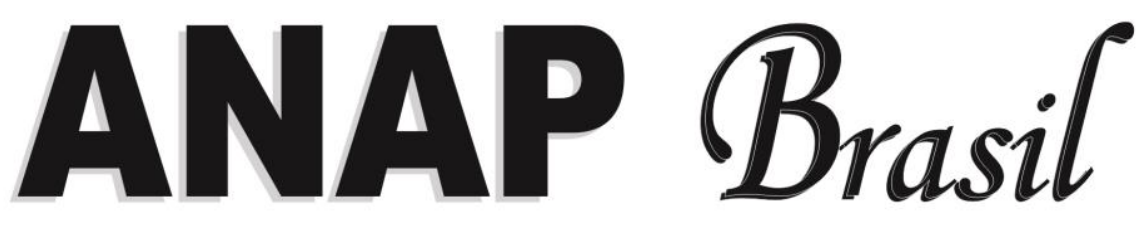

cidade de São Carlos (2018) que aponta como área urbana ocupada a quantidade de $33 \mathrm{~km}^{2}$ e, do sítio do IBGE (2018) que especula a população de 246.088 hab para o ano presente. Isto resulta em uma densidade de 71,59 hab/ha. Então tem-se que a área urbana da Bacia Hidrográfica tem aproximadamente 8.013 hab e a área de expansão com lotes de característica urbana (mínimo de $250 \mathrm{~m}^{2} /$ lote) terá uma população de aproximadamente 4.543 hab.

As áreas ocupadas por chácaras têm, em média, lotes a partir de $5.000 \mathrm{~m}^{2}$, o que equivale a 20 lotes urbanos. Desta premissa apontou-se a população de 2.017 hab para os condomínios de chácaras consolidados e a previsão de 239 hab para as áreas de expansão de condomínios de chácaras. Isto conduz a soma de 6.800 hab que não serão atendidos pelas estruturas atuais de tratamento de esgoto doméstico.

Para o cálculo do volume de esgoto gerado foram utilizados dados do sítio da Prefeitura (2018) e do SAAE (2018), que apontaram para o ano de 2014 a população de 238.950 hab e o tratamento de 21,6 milhões de $\mathrm{m}^{3}$ de esgoto doméstico (equivalente a $91 \%$ do efluente produzido). Isto estabelece a produção de $23,7 \mathrm{Mm}^{3}$ de esgoto por ano, o que leva a média de 272,1 L/hab/dia. Esta estimativa salienta que o volume de esgoto gerado será de aproximadamente $4.031,72 \mathrm{~m}^{3} /$ dia.

Segundo Godoy (2013), a parte que compõe a lodo desidratado corresponde a 0,04\% do volume do esgoto in natura, o que corresponde a 39,72 L/hab/ano para a produção de efluentes que correspondente a bacia hidrográfica. Esta informação foi parâmetro base para a adaptação da proposta de Von Sperling (2014) que apresenta um rol dos tratamentos de esgoto e suas combinações. A proposta foi tratada para as previstas condições específicas da bacia hidrográfica (volume de esgoto gerado e população) e dessa forma, gerou-se a Tabela 1, onde foram aferidos os tratamentos que comportavam a vazão exigida pela estimativa, e também as áreas exigidas pelos mesmos.

TABELA 2: Características típicas dos principais sistemas de tratamento de esgotos, expressos em valores das necessidades da projeção da expansão populacional.

\begin{tabular}{|c|c|c|c|c|c|c|}
\hline Sistema & $\begin{array}{c}\text { Área exigida } \\
\text { pelo } \\
\text { tratamento } \\
\left(\mathrm{m}^{2}\right)\end{array}$ & $\begin{array}{c}\text { Potência } \\
\text { consumida } \\
\text { na operação }\end{array}$ & $\begin{array}{c}\text { Lodo } \\
\text { desidratado a } \\
\text { ser disposto } \\
\text { (L/hab.ano) }\end{array}$ & $\begin{array}{l}\text { Custos (US\$ } \\
\text { Implantação } \\
\text { (R\$) }\end{array}$ & $\begin{array}{c}=\mathrm{R} \$ 3,7 / 2018) \\
\text { Operação e } \\
\text { manutenção } \\
\text { (R\$/ano) }\end{array}$ & $\begin{array}{c}\text { Eficiência } \\
\text { média - } \\
\text { Volume/área } \\
\text { (L/m².ano) }\end{array}$ \\
\hline $\begin{array}{c}\text { Tratamento primário } \\
\text { (tanques sépticos) }\end{array}$ & $450-750$ & Não & $15-35$ & $\begin{array}{l}609.000- \\
1.015 .000\end{array}$ & $32.000-51.000$ & 600 \\
\hline $\begin{array}{c}\text { Tratamento primário } \\
\text { convencional }\end{array}$ & $300-600$ & Não & $15-40$ & $\begin{array}{l}609.000- \\
1.015 .000\end{array}$ & $32.000-51.000$ & 875 \\
\hline $\begin{array}{c}\text { Tratamento primário } \\
\text { avançado }\end{array}$ & $600-900$ & Não & $40-110$ & $\begin{array}{l}819.000- \\
1.218 .000\end{array}$ & $\begin{array}{c}163.000- \\
306.000\end{array}$ & 1417 \\
\hline Lagoa facultativa & $\begin{array}{l}30.000- \\
60.000\end{array}$ & Não & $15-30$ & $\begin{array}{l}819.000- \\
1.624 .000\end{array}$ & $40.000-82.000$ & 8 \\
\hline
\end{tabular}




\section{ANAP \\ Brasil \\ ISSN 1984-3240 v. 12, n. 26}

\section{REVISTA C IENTÍF I C A}

\section{9}

\begin{tabular}{|c|c|c|c|c|c|c|}
\hline $\begin{array}{l}\text { Lagoa anaeróbia - lagoa } \\
\text { facultativa }\end{array}$ & $\begin{array}{l}22.000- \\
45.000\end{array}$ & Não & $20-60$ & $\begin{array}{l}609.000- \\
1.523 .000\end{array}$ & $40.000-82.000$ & 17 \\
\hline Lagoa aerada facultativa & $4.000-7.500$ & Sim & $7-30$ & $\begin{array}{c}1.015 .000- \\
1.827 .000\end{array}$ & $\begin{array}{l}103.000- \\
183.000\end{array}$ & 44 \\
\hline $\begin{array}{l}\text { Lagoa aerada mistura } \\
\text { completa - lagoa } \\
\text { sedimentação }\end{array}$ & $3.000-6.000$ & Sim & $10-30$ & $\begin{array}{c}1.015 .000- \\
1.827 .000\end{array}$ & $\begin{array}{c}103.000- \\
183.000\end{array}$ & 69 \\
\hline $\begin{array}{l}\text { Lagoa anaeróbia + lagoa } \\
\text { facultativa + lagoa de } \\
\text { maturação }\end{array}$ & $\begin{array}{l}45.000- \\
75.000\end{array}$ & Não & $20-60$ & $\begin{array}{c}1.015 .000- \\
2.030 .000\end{array}$ & $\begin{array}{l}51.000- \\
103.000\end{array}$ & 93 \\
\hline $\begin{array}{c}\text { Lagoa anaeróbia + lagoa } \\
\text { facultativa + lagoa de } \\
\text { alta taxa }\end{array}$ & $\begin{array}{l}30.000- \\
52.000\end{array}$ & Sim & $20-70$ & $\begin{array}{c}1.015 .000- \\
1.827 .000\end{array}$ & $\begin{array}{l}72.000- \\
122.000\end{array}$ & 15 \\
\hline $\begin{array}{l}\text { Lagoa anaeróbia + lagoa } \\
\text { facultativa + remoção de } \\
\text { algas }\end{array}$ & $\begin{array}{l}25.000- \\
47.500\end{array}$ & Não & $25-70$ & $\begin{array}{c}1.015 .000- \\
1.827 .000\end{array}$ & $\begin{array}{l}72.000- \\
122.000\end{array}$ & 18 \\
\hline Infiltração lenta & $\begin{array}{l}148.500- \\
741.000\end{array}$ & Não & - & $\begin{array}{l}406.000- \\
1.218 .000\end{array}$ & $21.000-61.000$ & 0 \\
\hline Infiltração rápida & $\begin{array}{c}15.000- \\
89.000\end{array}$ & Não & - & $\begin{array}{l}609.000- \\
1.421 .000\end{array}$ & $32.000-72.000$ & 0 \\
\hline Escoamento superficial & $\begin{array}{l}30.000- \\
52.000\end{array}$ & Não & - & $\begin{array}{l}812.000- \\
1.624 .000\end{array}$ & $40.000-82.000$ & 0 \\
\hline $\begin{array}{c}\text { Terras úmidas } \\
\text { construídas (wetlands) }\end{array}$ & $\begin{array}{l}44.500- \\
74.000\end{array}$ & Não & - & $\begin{array}{c}1.015 .000- \\
1.624 .000\end{array}$ & $51.000-82.000$ & 0 \\
\hline $\begin{array}{c}\text { Tanque séptico + filtro } \\
\text { anaeróbio }\end{array}$ & $3.000-5.200$ & Não & $25-50$ & $\begin{array}{c}1.624 .000- \\
2.639 .000\end{array}$ & $\begin{array}{c}122.000- \\
203.000\end{array}$ & 134 \\
\hline $\begin{array}{l}\text { Tanque séptico + } \\
\text { infiltração }\end{array}$ & $\begin{array}{l}15.000- \\
22.5000\end{array}$ & Não & $15-35$ & $\begin{array}{l}1218000- \\
2.030 .000\end{array}$ & $\begin{array}{l}61.000- \\
103.000\end{array}$ & 19 \\
\hline Reator UASB & $500-1.500$ & Não & $10-35$ & $\begin{array}{l}609.000- \\
1.015 .000\end{array}$ & $51.000-72.000$ & 342 \\
\hline UASB + lodos ativados & $1.200-3.000$ & Sim & $15-60$ & $\begin{array}{c}1.421 .000- \\
2.233 .000\end{array}$ & $\begin{array}{c}143.000- \\
243.000\end{array}$ & 244 \\
\hline $\begin{array}{l}\text { UASB + biofiltro aerado } \\
\text { submerso }\end{array}$ & $800-2.300$ & Sim & $15-55$ & $\begin{array}{c}1.321 .000- \\
2.030 .000\end{array}$ & $\begin{array}{l}143.000- \\
243.000\end{array}$ & 333 \\
\hline UASB + filtro anaeróbio & $800-2.300$ & Não & $10-50$ & $\begin{array}{l}915.000- \\
1.421 .000\end{array}$ & $\begin{array}{l}72.000- \\
112.000\end{array}$ & 267 \\
\hline $\begin{array}{l}\text { UASB + filtro biológioo } \\
\text { percolador de alta carga }\end{array}$ & $1.500-3.000$ & Não & $15-55$ & $\begin{array}{l}1.218 .000- \\
1.827 .000\end{array}$ & $\begin{array}{l}103.000- \\
153.000\end{array}$ & 213 \\
\hline $\begin{array}{c}\text { UASB + flotação por ar } \\
\text { dissolvido }\end{array}$ & $800-2.300$ & Sim & $25-75$ & $\begin{array}{l}1.218 .000- \\
1.827 .000\end{array}$ & $\begin{array}{l}122.000- \\
183.000\end{array}$ & 500 \\
\hline $\begin{array}{l}\text { UASB + lagoas de } \\
\text { polimento }\end{array}$ & $\begin{array}{c}22.500- \\
37.000\end{array}$ & Não & $10-35$ & $\begin{array}{l}819.000- \\
1.421 .000\end{array}$ & $\begin{array}{l}92.000- \\
143.000\end{array}$ & 10 \\
\hline
\end{tabular}




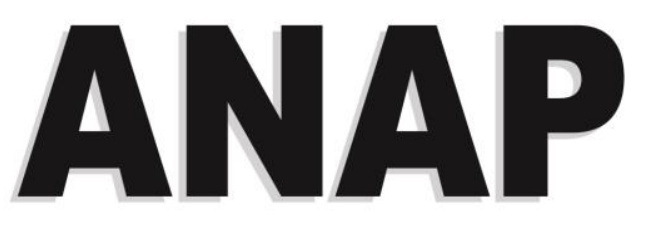

Brasil

ISSN 1984-3240

REVISTA CIENTÍFICA

2019

\begin{tabular}{|c|c|c|c|c|c|c|}
\hline $\begin{array}{l}\text { UASB + lagoa aerada } \\
\text { facultativa }\end{array}$ & $2.300-4.500$ & Sim & $15-50$ & $\begin{array}{l}812.000- \\
1.827 .000\end{array}$ & $\begin{array}{l}103.000- \\
183.000\end{array}$ & 133 \\
\hline $\begin{array}{l}\text { UASB + lagoa aerada } \\
\text { mist. compl. + lagoa } \\
\text { decantação }\end{array}$ & $1.500-4.500$ & Sim & $15-50$ & $\begin{array}{l}819.000- \\
1.827 .000\end{array}$ & $\begin{array}{l}103.000- \\
183.000\end{array}$ & 158 \\
\hline $\begin{array}{l}\text { UASB + escoamento } \\
\text { superficial }\end{array}$ & $\begin{array}{l}22.300- \\
44.500\end{array}$ & Não & $10-35$ & $\begin{array}{c}1.015 .000- \\
1.827 .000\end{array}$ & $\begin{array}{l}103.000- \\
143.000\end{array}$ & 9 \\
\hline $\begin{array}{l}\text { Lodos ativados } \\
\text { convencional }\end{array}$ & $1.800-3.800$ & Sim & $35-90$ & $\begin{array}{c}2.030 .000- \\
3.249 .000\end{array}$ & $\begin{array}{l}203.000- \\
406.000\end{array}$ & 326 \\
\hline $\begin{array}{l}\text { Lodos ativados - aeração } \\
\text { prolongada }\end{array}$ & $1.800-3.800$ & Sim & $40-105$ & $\begin{array}{c}1.827 .000- \\
2.436 .000\end{array}$ & $\begin{array}{l}203.000- \\
406.000\end{array}$ & 377 \\
\hline $\begin{array}{l}\text { Lodos ativados - batelada } \\
\text { (aeração prolongada) }\end{array}$ & $1.800-3.800$ & Sim & $40-105$ & $\begin{array}{c}1.827 .000- \\
2.436 .000\end{array}$ & $\begin{array}{l}203.000- \\
406.000\end{array}$ & 377 \\
\hline $\begin{array}{l}\text { Lodos ativados } \\
\text { convencional com } \\
\text { remoção biológica de } \mathrm{N}\end{array}$ & $1.800-3.800$ & Sim & $35-90$ & $\begin{array}{c}2.233 .000- \\
3.452 .000\end{array}$ & $\begin{array}{l}203.000- \\
446.000\end{array}$ & 326 \\
\hline $\begin{array}{l}\text { Lodos ativados } \\
\text { convencional com } \\
\text { remoção biológica de } \\
\text { N/P }\end{array}$ & $1.800-3.800$ & Sim & $35-90$ & $\begin{array}{c}2.639 .000- \\
3.858 .000\end{array}$ & $\begin{array}{l}306.000- \\
509.000\end{array}$ & 326 \\
\hline $\begin{array}{c}\text { Lodos ativados } \\
\text { convencional + filtração } \\
\text { terciária }\end{array}$ & $2.300-4.500$ & Sim & $40-100$ & $\begin{array}{c}2.639 .000- \\
3.858 .000\end{array}$ & $\begin{array}{l}306.000- \\
509.000\end{array}$ & 300 \\
\hline $\begin{array}{c}\text { Filtro biológico } \\
\text { percolador de baixa } \\
\text { carga }\end{array}$ & $2.300-4.500$ & Não & $35-80$ & $\begin{array}{c}2.436 .000- \\
3.046 .000\end{array}$ & $\begin{array}{l}203.000- \\
306.000\end{array}$ & 250 \\
\hline $\begin{array}{l}\text { Filtro biológico } \\
\text { percolador de alta carga }\end{array}$ & $1.800-3.800$ & Não & $35-80$ & $\begin{array}{c}2.436 .000- \\
3.046 .000\end{array}$ & $\begin{array}{l}203.000- \\
306.000\end{array}$ & 306 \\
\hline $\begin{array}{l}\text { Biofiltro aerado } \\
\text { submerso com } \\
\text { nitrificação }\end{array}$ & $1.500-2.300$ & Sim & $35-90$ & $\begin{array}{c}1.421 .000- \\
2.436 .000\end{array}$ & $\begin{array}{l}163.000- \\
306.000\end{array}$ & 475 \\
\hline $\begin{array}{c}\text { Biofiltro aerado } \\
\text { submerso com remoção } \\
\text { biológica de } \mathrm{N}\end{array}$ & $1.500-2.300$ & Sim & $35-90$ & $\begin{array}{l}1.624 .000- \\
2.639 .000\end{array}$ & $\begin{array}{l}163.000- \\
306.000\end{array}$ & 475 \\
\hline $\begin{array}{c}\text { Tanque séptico + } \\
\text { biodisco }\end{array}$ & $1.500-3.000$ & Não & $20-75$ & $\begin{array}{c}2.436 .000- \\
3.046 .000\end{array}$ & $\begin{array}{c}203.000- \\
306.000\end{array}$ & 288 \\
\hline
\end{tabular}

Fonte: Autores, adaptação de Von Sperling (2014).

Os tipos de tratamentos que respeitam os parâmetros estabelecidos são os Reatores UASB, somados de Flotação por ar dissolvido ou Biofiltro aerado submerso. Estes tratamentos atendem a demanda sendo compactos e com baixo custo de implantação e operação. A compacidade foi estimada pelo comparativo da área que o atual tratamento contempla em 


\section{ANAP

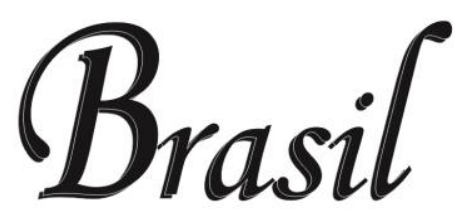 \\ ISSN 1984-3240 V. 12, n. 26}

\section{REVISTA CIENTÍFICA}

relação a população que atende, o que remete a uma área de aproximadamente $6.000 \mathrm{~m}^{2}$ de terreno e $1.200 \mathrm{~m}^{2}$ de área reservada para o tratamento (Tabela 2).

TABELA 3: Características típicas dos principais sistemas de tratamento de esgotos coerentes com os parâmetros adaptados pela metodologia do estudo.

\begin{tabular}{|c|c|c|c|c|c|c|}
\hline \multirow{2}{*}{ Sistema } & \multirow{2}{*}{$\begin{array}{c}\text { Área exigida } \\
\text { pelo } \\
\text { tratamento } \\
\qquad\left(\mathrm{m}^{2}\right)\end{array}$} & \multirow{2}{*}{$\begin{array}{c}\text { Potência } \\
\text { consumida na } \\
\text { operação }\end{array}$} & \multirow{2}{*}{$\begin{array}{c}\text { Lodo } \\
\text { desidratado a } \\
\text { ser disposto } \\
\text { (L/hab.ano) }\end{array}$} & \multicolumn{2}{|c|}{ Custos (US\$1=R\$3,7/2018) } & \multirow{2}{*}{$\begin{array}{c}\text { Eficiência por } \\
\text { área - } \\
\text { Volume/área } \\
\text { (L/m².ano) }\end{array}$} \\
\hline & & & & $\begin{array}{l}\text { Implantação } \\
\text { (R\$) }\end{array}$ & $\begin{array}{c}\text { Operação e } \\
\text { manutenção } \\
\text { (R\$/ano) }\end{array}$ & \\
\hline $\begin{array}{l}\text { UASB + biofiltro aerado } \\
\text { submerso }\end{array}$ & $800-2.300$ & Sim & $15-55$ & $\begin{array}{l}1.321 .000- \\
2.030 .000\end{array}$ & $\begin{array}{c}143.000- \\
243.000\end{array}$ & 333 \\
\hline $\begin{array}{c}\text { UASB + flotação por ar } \\
\text { dissolvido }\end{array}$ & $800-2.300$ & Sim & $25-75$ & $\begin{array}{c}1.218 .000- \\
1.827 .000\end{array}$ & $\begin{array}{c}122.000- \\
183.000\end{array}$ & 500 \\
\hline
\end{tabular}

Fonte: Autores.

Foram retiradas informações do sítio da Prefeitura (2018) sobre os custos da ampliação da ETE - Monjolinho para traçar um paralelo com o custo de implantação de novas estações de tratamento de esgoto compactas. Os custos de manutenção e operação da ETE foram retirados do sítio do portal de transparência do SAAE (2018), valor de referência de 2017. Destes custos foi traçado um equivalente comparando a população atendida pela gasto e a perspectiva do gasto com a projeção da população para a área de estudo. $O$ custo das estações elevatórias foram calculadas pela equação 1, proposta por Colossi (2002) e para as 3 estações elevatórias previstas pelo Plano Municipal de Saneamento do Município de São Carlos (PMSSanCa) o montante alcança R\$ 500.000.

$$
y=3290 \times L^{0,330} \times X^{0,679}
$$

y: custo em dólares (US\$)

$\mathrm{L}$ : altura manométrica $(\mathrm{m})$

$\mathrm{X}$ : vazão (L/s)

Segundo Pacheco (2011), os custos mínimos para implementação da rede coletora giram em torno de $\mathrm{R} \$ 408,88$ por habitante, podendo aumentar para redes menores. Com isso, teremos um valor mínimo de aproximadamente $\mathrm{R} \$ 2.780 .000,00$ para a implantação do sistema de coleta de efluentes domésticos para as áreas que ainda não tem sistema de coleta de esgoto.

Para um comparativo com o atual sistema de tratamento de esgoto doméstico do município foi identificada uma fração equivalente à perspectiva de população da expansão urbana da área de estudo correlacionada com o custo e produção de esgoto pelo município, com as referências da população do município. Está em fase de implementação a ampliação da ETE Monjolinho que pretende tratar $319 \mathrm{~L} / \mathrm{s}$ ao custo de R\$ 29 milhões. O equivalente para a previsão da vazão de esgoto doméstico $(46,6 \mathrm{~L} / \mathrm{s})$ da população estimada soma $\mathrm{R} \$$ 4,16 milhões. E quando levantado o custo de manutenção e operação para o ano de 2017 , os 
LEITE, G. S.; AFONSO, R. J. C. F.; AQUINO, S. F. Caracterização de contaminantes presentes em sistemas de tratamento de esgotos, por cromatografia líquida acoplada à espectrometria de massas tandem em alta resolução. Quim. Nova, Vol. 33, No. 3, 734-738, 2010.

MERTEN, G. H.; MINELLA, J. P. Qualidade da água em bacias hidrográficas rurais: um desafio atual para a sobrevivência futura. Agroecol. e Desenvol. Rur. Sustent. Porto Alegre, v.3, n.4, out/dez 2002.

PACHECO, R. P. Custos Para Implantação De Sistemas De Esgotamento Sanitário. 2011. 149 f. Dissertação (Mestrado em Engenharia de Recursos Hídricos e Ambiental). Programa de Pós-Graduação em Engenharia de Recursos Hídricos e Ambiental, Setor de Tecnologia. Universidade Federal do Paraná. Curitiba. 2011.

PNUD, IPEA, FJP - Atlas do Desenvolvimento Humano do Brasil. Perfil: São Carlos - SP (2013). Disponível em: <http://www.atlasbrasil.org.br/2013/pt/perfil_m/sao-carlos_sp>. Acesso em: 21 Mai. 2018.

PRADO, G. S. Concepção e estudo de uma unidade compacto para tratamento preliminar de esgoto sanitário composta por separador hidrodinâmico por vórtice e grade fina de fluxo tangencial. 240p. Tese (Doutorado) Escola de Engenharia de São Carlos, Universidade de São Paulo, São Carlos, 2006.

RIBEIRO, J. W.; ROOKE, J. M. S. Saneamento básico e sua relação com o meio ambiente e a saúde pública. Trabalho de Conclusão de Curso - Curso de Especialização em Análise Ambiental, Universidade Federal de Juiz de Fora, 2010.

SAAE - Serviço autônomo de Água e Esgoto. Sistemas de Tratamento de Esgoto. Aracruz, junho de 2006.

- - Dados de Saneamento: Produção de Água e Esgoto Tratado. Disponível em: <http://www.saaesaocarlos.com.br/joomla4/index.php/dadossaneamentomenutop/producaoaguaeesgotomenu>. Acesso em: 21 Mai. 2018.

_ - Portal de Transparência. Despesas. Disponível em: <http://transparencia.cebi.com.br/031/Despesa/Despesas>. Acesso em: 14 Jun. 2018.

SÃO CARLOS (Município). Prefeitura Municipal. Coordenadoria do Meio Ambiente. Plano Municipal de Saneamento - São Carlos/SP - PMSSanCa, 2012. São Carlos, 2012. 421 p.

- Conheça São Carlos. Dados da Cidade (Geográfico e Demográfico). Disponível em: <http://www.saocarlos.sp.gov.br/index.php/conheca-sao-carlos/115442-dados-da-cidade-geografico-edemografico.html>. Acesso em: 21 Mai. 2018.

STANGANINI, F. N; LOLLO, J. A.; RÖHM, S. A. Diagnóstico ambiental da sub-bacia do Chibarro no município de São Carlos/SP, considerando o uso e ocupação da terra. In: Pluris 7., 2016, Maceió - AL. Anais: Fau - UFAL. Maceió: UFAL, 2016. Paper 1102.

TEODORO, V. L. I.; TEIXEIRA, D.; COSTA, D. J. L.; FULLER, B. B. O conceito de bacia hidrográfica e a importância da caracterização morfométrica para o entendimento da dinâmica ambiental local. REVISTA UNIARA, n.20, 2007.

USGS. United States Geological Survey. Science for a changing world. Disponível em: <https://earthexplorer.usgs.gov/>. Acesso em: 08 maio 2018.

VAZ, A. P. R.; DUCATTI, M. L.; PASQUALETTO, A. avaliação de impactos ambientais nas estações de tratamento de esgotos sanitários: ETE - Lajes, Aparecida de Goiânia - GO. Artigo Científico apresentado ao Serviço Nacional de 


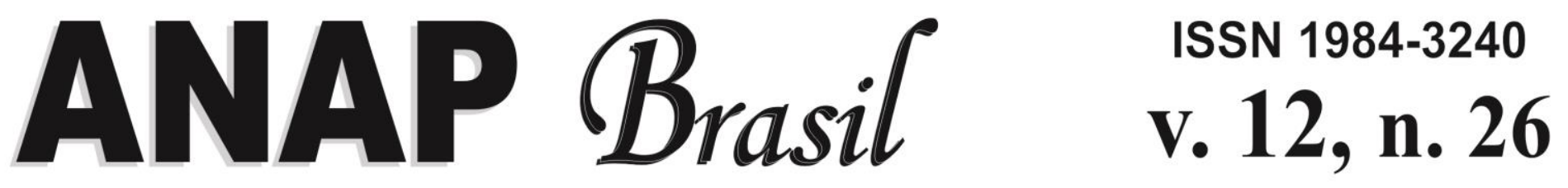

\section{REVISTA C I EN TÍF I C A 2019}

Aprendizagem Industrial (SENAI) e Universidade Católica de Goiás (UCG) no curso de Especialização em Gestão Ambiental. 2003.

VON SPERLING, M. Introdução á qualidade das águas e ao tratamento de esgotos. 4a Edição. Editora: UFMG. 2014.

YAMADA, T. Ferramentas de geoprocessamento para a análise da vulnerabilidade natural das águas subsuperficiais à poluição, área urbana e seu entorno, município de São Carlos - SP. 2007. 67 f. Dissertação (Pósgraduação em Engenharia Urbana), Centro de Ciências Exatas e Tecnologia, Universidade Federal de São Carlos, 2007. 